\title{
The Writing On The Wall Intravitreal Injection Compliance During The COVID-19 Pandemic and Its Foreseeable Consequences
}

Lauren M Wasser ( $\square$ lauriew21@gmail.com )

Shaare Zedek Medical Center https://orcid.org/0000-0002-6093-1996

Yishay Weill

Shaare Zedek Medical Center

Koby Brosh

Shaare Zedek Medical Center

Itay Magal

Shaare Zedek Medical Center

Michael Potter

Shaare Zedek Medical Center

Israel Strassman

Shaare Zedek Medical Center

\section{Evgeny Gelman}

Shaare Zedek Medical Center

\section{Meni Koslowsky}

Ariel University

\section{David Zadok}

Shaare Zedek Medical Center Joel Hanhart

Shaare Zedek Medical Center

\section{Research}

Keywords: intravitreal injections, coronavirus, pandemic, compliance

Posted Date: August 6th, 2020

DOI: https://doi.org/10.21203/rs.3.rs-53248/v1

License: (1) (1) This work is licensed under a Creative Commons Attribution 4.0 International License.

Read Full License 


\section{Abstract}

Background: Intravitreal injections (IVI) of anti-vascular endothelial growth factor (anti-VEGF) agents have become the most prevalent intraocular procedure as they represent the major therapeutic modality for prevalent retinal conditions such as age-related macular degeneration (AMD) and diabetic retinopathy. Effective therapy requires adherence to a schedule of iterative IVI as well as routine clinic appointments. The ongoing Coronavirus disease 2019 (COVID-19) pandemic has resulted in the reduction of attendance at scheduled clinics visits and IVI. In this study we attempted to analyze the effect of COVID-19 on compliance with anti-VEGF therapy.

Methods: A total of 636 eyes received injections during a four-week period of the COVID-19 outbreak in the Retina Clinic. The number of clinic visits for IVI during one month from March 15 to April 14 of 2020 was compared to the similar time period in each of the last four years.

Results: The study demonstrates a decrease in clinic visits for IVI when compared with the same fourweek interval in the four previous years. Based on the trend of the previous four years, $10.2 \%$ of the year's total was expected for this time period. Using this model, the 636 reported number of injections for the March-April, 2020 period was 5\%. This represents a decrease of $\sim 50 \%$ of the expected IVI for this time period.

Conclusion: The COVID-19 outbreak in Israel severely impacted compliance with anti-VEGF treatments.

\section{Background}

Intravitreal injections (IVI) are a prevalent intraocular procedure in the ophthalmology clinic and have been described to treat various retinal pathologies(1). Individuals often receive serial injections and require these treatments on a regular basis(2). Compliance with the treatment prescription is crucial(3-8). Even slight deviations may be associated with decreased vision(9). The Coronavirus (COVID-19) outbreak in Israel resulted in a curtailment of ophthalmologic clinic appointments. This began in mid-March 2020 by order of the Ministry of Health of the State of Israel in order for hospitals and healthcare facilities to accommodate the onslaught of COVID-19 patients. To assess the risk of potential visual loss, we compared IVI clinic attendance during the pandemic to clinic attendance in previous years.

\section{Methods}

\section{Data Collection}

Initially, the number of intravitreal injections performed at the Shaare Zedek Medical Center retina clinic during four weeks of the COVID-19 pandemic March 15 to April 142020 was analyzed. Injections with anti-vascular endothelial growth factor (anti-VEGF) agents bevacizumab (Avastin), ranibizumab (Lucentis) and aflibercept (Eylea) were analyzed jointly and individually. These results were compared to the same time period in the previous four years, March 15 to April 14 2016, 2019. The Shaare Zedek 
Medical Center Institutional Ethics Committee approved the study and did not require an individual informed consent from the subjects. All indications for anti-VEGF were included, regardless of diagnosis, duration of treatment or previous compliance to the injection schedule. Individual injections were tabulated and patients who received treatment for both eyes were counted twice.

\section{Statistical Analysis}

All data collected in this study were analyzed using SPSS software (SPSS 24.0, SPSS Science, Chicago, IL, USA). Linear regression was performed for the present analysis.

\section{Results}

A total of 636 injections were performed during the period of the COVID-19 outbreak in Israel, from March 152020 to April 142020 (Table 1). Of these, there were 364 injections of bevacizumab, 75 injections of ranibizumab and 197 injections of aflibercept. These injections were compared to the injections performed in March 15 to April 14 of the four previous years during which time the number of IVI in the retina clinic steadily increased. The gradual increase of IVI during these four weeks is consistent with the annual increase in IVI in our center over the last several years. In 2015, 6880 injections were performed, 8143 in 2016, 8547 in 2017, 10570 in 2018, and 12349 in 2019. When comparing March 152020 to April 142020 to the same period in 2019, we see an overall drop of $36 \%$ for all IVI: $44 \%$ for bevacizumab, $17 \%$ for ranibizumab and $22 \%$ for aflibercept. For this period of time we have precise figures and the MarchApril proportion is approximately $10.2 \%$ of the year's total. Using a linear regression approach for analyzing the data, the findings showed a very clear and significant trend (adjusted R2 $=.552, \mathrm{p}<.001$ ). Based on this model, it was expected that the injections would increase to 12,672 in 2020 . As a proportion of what is expected for the entire year, the 636 reported number of injections for the MarchApril, 2020 period was about $5 \%$, less than half the actual proportion observed in previous years.

Figure 2 represents the downward trend IVI over the time associated with the COVID-19 outbreak milestones in Israel. From the week of February 20th 2020 to the week of April 1st 2020, there was a 58\% decrease of total IVI: $60 \%$ for bevacizumab, $61 \%$ for ranibizumab and $50 \%$ for aflibercept.

\section{Discussion}

This analysis demonstrates a marked decrease in IVI of anti-VEGF agents delivered during a four-week period of the COVID-19 outbreak. The decrease in IVI correlated with the advancing coronavirus outbreak in Israel, namely increasing numbers of individuals testing positive for the virus, hospitalizations and deaths. The outbreak resulted in an increase in governmental restriction on local and foreign travel and quarantine of Jerusalem neighborhoods. Hospital services including elective surgeries and clinics were curtailed. Although IVI were considered essential clinic visits and this service was not curtailed, this study indicates that many individuals requiring IVI chose not to attend previously scheduled appointments. 
Compliance in individuals obtaining IVI has been previously described to vary based on the treated condition $(10,11)$. There is currently no data on the effect of a pandemic on IVI clinic visit. The risk for mortality from COVID-19 rises substantially in individuals older than 65 years of age(12), those living in skilled nursing facilities (13) and individuals with co-morbidities such as diabetes(14) and obesity(15). As the two major indications for iterative IVI are neovascular AMD and diabetic ocular complications(16-18), these individuals are precisely those at highest risk for COVID-19 associated mortality. Furthermore, since viral transmission has been documented in asymptomatic individuals, it is understandable that an ophthalmologic patient may be fearful regarding exposure to coronavirus at a crowded outpatient hospital(19-21).

As ophthalmologic specialists, we are necessarily concentrating our efforts on the ophthalmologic care of our patients and are concerned about resultant potential vision loss from missing IVI(22). However, in this circumstance, it is our duty to balance the desire to treat their ophthalmic disease while protecting them from being harmed from inadvertent viral transmission(22-31). Several ways may be considered to improve delivery of retinal care(32). One option is to provide home injections with appropriate protection of the healthcare workers(33). A second option may be to concentrate IVI in skilled nursing facilities and day care centers. Thirdly, albeit a more distant goal, is accelerating development of long acting anti-VEGF therapeutics which would reduce the frequency of clinic visits.

Limitations include the relatively brief period and the single center nature of the study.

\section{Conclusions}

During the four-week period of the COVID-19 outbreak in Israel, we observed a greater than $50 \%$ drop in attendance at the IVI in our Retina Clinic. It became evident that many of our patients were being lost to follow-up. This marked decrease in attendance is understandable taking into consideration that many of these individuals exhibit co-morbidities that place them at increased risk for mortality should they contract COVID-19 infection. It is imperative, however, that we recognize the "writing on the wall" and begin to plan for the consequences of this missed therapy. We therefore reached out to patients and their families to demonstrate our concern. We wished to make every effort to better understand how they were coping with the outbreak, and to remind them that should they experience any visual changes that we, their ophthalmologists, are here for them (Figure 2).

\section{Declarations}

Ethics Approval: . The Shaare Zedek Medical Center Institutional Ethics Committee approved the study and did not require an individual informed consent from the subjects.

Consent for Publication: Not applicable

Availability of Data and Materials: The datasets analyzed during the current study are not publicly available due the concern for patient safety and confidentiality but are available from the corresponding 
author upon reasonable request.

Competing Interests: All authors declare no competing interests.

Funding: No funding was received for this study.

Acknowledgements: Not applicable

\section{References}

1. Parikh R, Pirakitikulr N, Chhablani J, Sakurada Y, Singh RP, Modi YS. A Multinational Comparison of Anti-Vascular Endothelial Growth Factor Use: The United States, the United Kingdom, and AsiaPacific. Ophthalmology Retina. 2019;3(1):16-26.

2. Haller JA. Current anti-vascular endothelial growth factor dosing regimens: benefits and burden. Ophthalmology. 2013;120(5 Suppl):S3-7.

3. Angermann R, Rauchegger T, Nowosielski Y, Casazza M, Bilgeri A, Ulmer H, et al. Treatment compliance and adherence among patients with diabetic retinopathy and age-related macular degeneration treated by anti-vascular endothelial growth factor under universal health coverage. Graefe's archive for clinical and experimental ophthalmology = Albrecht von Graefes Archiv fur klinische und experimentelle Ophthalmologie. 2019;257(10):2119-25.

4. Sun JK, Wang PW, Taylor S, Haskova Z. Durability of Diabetic Retinopathy Improvement with AsNeeded Ranibizumab: Open-Label Extension of RIDE and RISE Studies. Ophthalmology. 2019;126(5):712-20.

5. Campochiaro PA, Wykoff CC, Singer M, Johnson R, Marcus D, Yau L, et al. Monthly versus as-needed ranibizumab injections in patients with retinal vein occlusion: the SHORE study. Ophthalmology. 2014;121(12):2432-42.

6. Ehlken C, Helms M, Bohringer D, Agostini HT, Stahl A. Association of treatment adherence with reallife VA outcomes in AMD, DME, and BRVO patients. Clinical ophthalmology (Auckland, NZ). 2018;12:13-20.

7. Regillo CD, Brown DM, Abraham P, Yue H, lanchulev T, Schneider S, et al. Randomized, doublemasked, sham-controlled trial of ranibizumab for neovascular age-related macular degeneration: PIER Study year 1. American journal of ophthalmology. 2008;145(2):239-48.

8. Ziemssen F, Feltgen N, Holz FG, Guthoff R, Ringwald A, Bertelmann T, et al. Demographics of patients receiving Intravitreal anti-VEGF treatment in real-world practice: healthcare research data versus randomized controlled trials. BMC ophthalmology. 2017;17(1):7.

9. Massamba N, Dirani A, Knoeri J, Pasquier B, Ingram A, Soubrane G. Evaluating the impact of summer vacation on the visual acuity of AMD patients treated with ranibizumab. Eye (London, England). 2015;29(11):1453-7.

10. Weiss M, Sim DA, Herold T, Schumann RG, Liegl R, Kern C, et al. COMPLIANCE AND ADHERENCE OF PATIENTS WITH DIABETIC MACULAR EDEMA TO INTRAVITREAL ANTI-VASCULAR ENDOTHELIAL 
GROWTH FACTOR THERAPY IN DAILY PRACTICE. Retina (Philadelphia, Pa). 2018;38(12):2293-300.

11. Polat O, İnan S, Özcan S, Doğan M, Küsbeci T, Yavaş GF, et al. Factors Affecting Compliance to Intravitreal Anti-Vascular Endothelial Growth Factor Therapy in Patients with Age-Related Macular Degeneration. Turk J Ophthalmol. 2017;47(4):205-10.

12. Pan A, Liu L, Wang C, Guo H, Hao X, Wang Q, et al. Association of Public Health Interventions With the Epidemiology of the COVID-19 Outbreak in Wuhan, China. Jama. 2020.

13. American Geriatrics Society (AGS) Policy Brief: COVID-19 and Nursing Homes. Journal of the American Geriatrics Society. 2020.

14. Stoian AP, Banerjee Y, Rizvi AA, Rizzo M. Diabetes and the COVID-19 Pandemic: How Insights from Recent Experience Might Guide Future Management. Metabolic syndrome and related disorders. 2020.

15. Simonnet A, Chetboun M, Poissy J, Raverdy V, Noulette J, Duhamel A, et al. High prevalence of obesity in severe acute respiratory syndrome coronavirus-2 (SARS-CoV-2) requiring invasive mechanical ventilation. Obesity (Silver Spring, Md). 2020.

16. Wecker T, Ehlken C, Buhler A, Lange C, Agostini H, Bohringer D, et al. Five-year visual acuity outcomes and injection patterns in patients with pro-re-nata treatments for AMD, DME, RVO and myopic CNV. The British journal of ophthalmology. 2017;101(3):353-9.

17. Pham B, Thomas SM, Lillie E, Lee T, Hamid J, Richter T, et al. Anti-vascular endothelial growth factor treatment for retinal conditions: a systematic review and meta-analysis. BMJ open. 2019;9(5):e022031.

18. Jain P, Sheth J, Anantharaman G, Gopalakrishnan M. Real-world evidence of safety profile of intravitreal bevacizumab (Avastin) in an Indian scenario. Indian journal of ophthalmology. 2017;65(7):596-602.

19. Lima CKT, Carvalho PMM, Lima I, Nunes J, Saraiva JS, de Souza RI, et al. The emotional impact of Coronavirus 2019-nCoV (new Coronavirus disease). Psychiatry research. 2020;287:112915.

20. Wang C, Pan R, Wan X, Tan Y, Xu L, Ho CS, et al. Immediate Psychological Responses and Associated Factors during the Initial Stage of the 2019 Coronavirus Disease (COVID-19) Epidemic among the General Population in China. International journal of environmental research and public health. 2020;17(5).

21. The L. COVID-19: protecting health-care workers. Lancet (London, England). 2020;395(10228):922.

22. Minocha A, Sim SY, Than J, Vakros G. Survey of ophthalmology practitioners in A\&E on current COVID-19 guidance at three Major UK Eye Hospitals. Eye (London, England). 2020.

23. Olivia Li J-P, Shantha J, Wong TY, Wong EY, Mehta J, Lin H, et al. Preparedness among Ophthalmologists: During and Beyond the COVID-19 Pandemic. Ophthalmology. 2020;127(5):569-72.

24. Borrelli E, Sacconi R, Querques L, Zucchiatti I, Prascina F, Bandello F, et al. Taking the right measures to control COVID-19 in ophthalmology: the experience of a tertiary eye care referral center in Italy. Eye (London, England). 2020. 
25. Du $H$, Zhang $M$, Zhang $H$, Sun $X$. Practical experience on emergency ophthalmic surgery during the prevalence of COVID-19. Graefe's archive for clinical and experimental ophthalmology = Albrecht von Graefes Archiv fur klinische und experimentelle Ophthalmologie. 2020.

26. Lim LW, Yip LW, Tay HW, Ang XL, Lee LK, Chin CF, et al. Sustainable practice of ophthalmology during COVID-19: challenges and solutions. Graefe's archive for clinical and experimental ophthalmology = Albrecht von Graefes Archiv fur klinische und experimentelle Ophthalmologie. 2020.

27. Ma X, Lin J, Fang S. Precautions in ophthalmic practice in a hospital with the risk of COVID-19: experience from China. Acta ophthalmologica. 2020.

28. Petrovski BE, Lumi X, Znaor L, Ivastinovic D, Confalonieri F, Petrovic MG, et al. Reorganize and survive-a recommendation for healthcare services affected by COVID-19-the ophthalmology experience. Eye (London, England). 2020.

29. Romano MR, Montericcio A, Montalbano C, Raimondi R, Allegrini D, Ricciardelli G, et al. Facing COVID-19 in Ophthalmology department. Current eye research. 2020.

30. Sadhu S, Agrawal R, Pyare R, Pavesio C, Zierhut M, Khatri A, et al. COVID-19: Limiting the Risks for Eye Care Professionals. Ocular immunology and inflammation. 2020:1-7.

31. Li KZ, Yong VKY, Lee LKM, Chin CF, Yip LWL. When ophthalmologists step up to the COVID-19 frontlines. Eye (London, England). 2020.

32. Shih CK, Chan JCH, Lai JSM. Maintenance of ophthalmic specialist out-patient service during the COVID-19 outbreak: The University of Hong Kong experience. Eye (London, England). 2020.

33. Starr MR, Barkmeier AJ, Engman SJ, Kitzmann A, Bakri SJ. Telemedicine in the Management of Exudative Age-Related Macular Degeneration within an Integrated health care System. Am J Ophthalmol. 2019;208:206-10.

\section{Tables}

Table 1. Number of intravitreal injections during four weeks of the COVID-19 pandemic as compared to the same month in previous years

\begin{tabular}{|lllll|}
\hline March 15 to April 14 & Bevacizumab & Ranibizumab & Aflibercept & Total \\
\cline { 2 - 5 } & & & & \\
\hline 2016 & 614 & 130 & 40 & 784 \\
\hline 2017 & 531 & 87 & 115 & 733 \\
\hline 2018 & 523 & 57 & 152 & 732 \\
\hline 2019 & 654 & 90 & 251 & 995 \\
\hline 2020 & 364 & 75 & 197 & 636 \\
\hline
\end{tabular}


As compared to the same period in 2019 , there is a decrease for all intravitreally injected anti-VEGF compounds. Throughout the five years presented, bevacizumab reached a low point during the COVID-19 crisis.

\section{Figures}

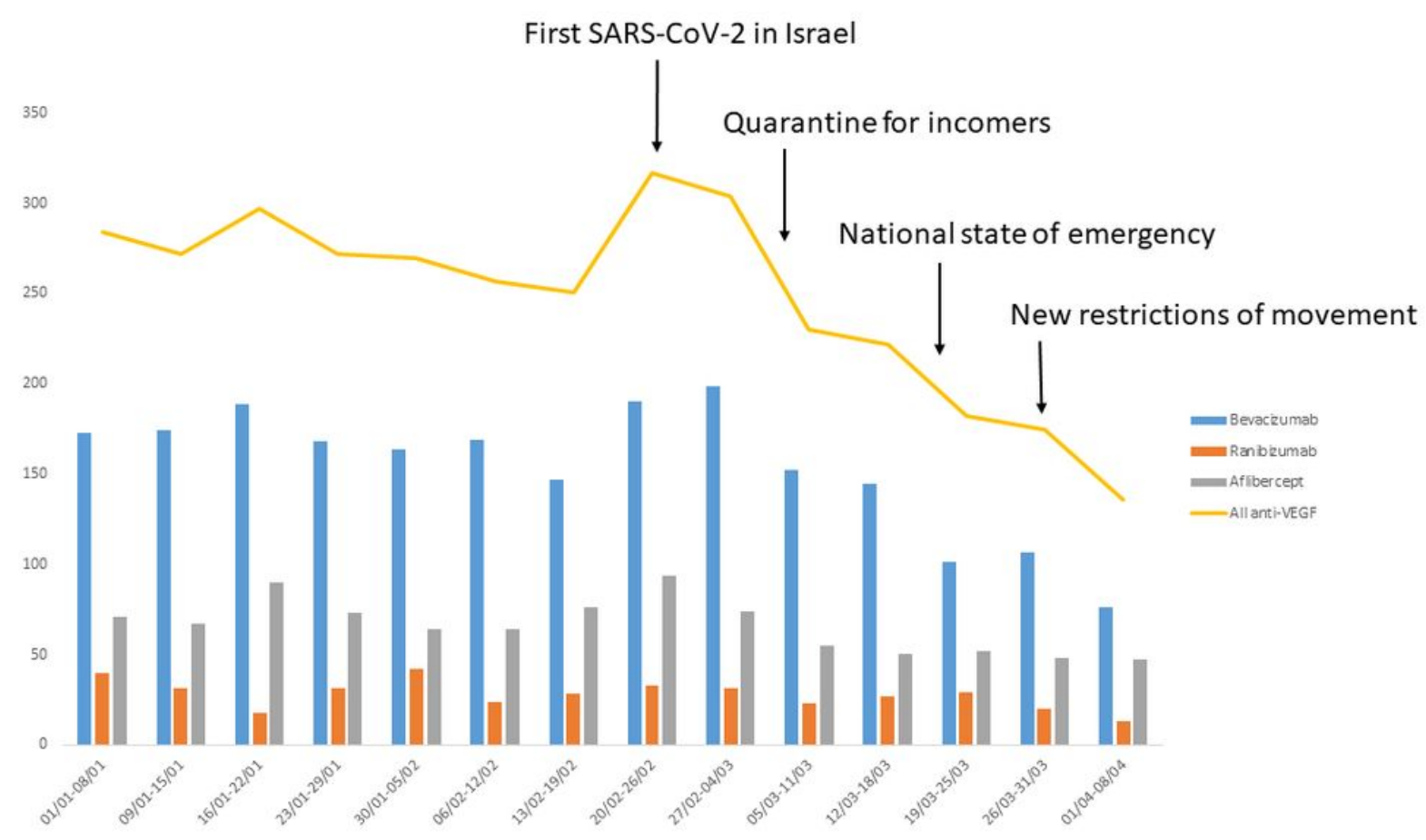

Figure 1

As governmental measures became more stringent, the number of delivered injections dropped. 


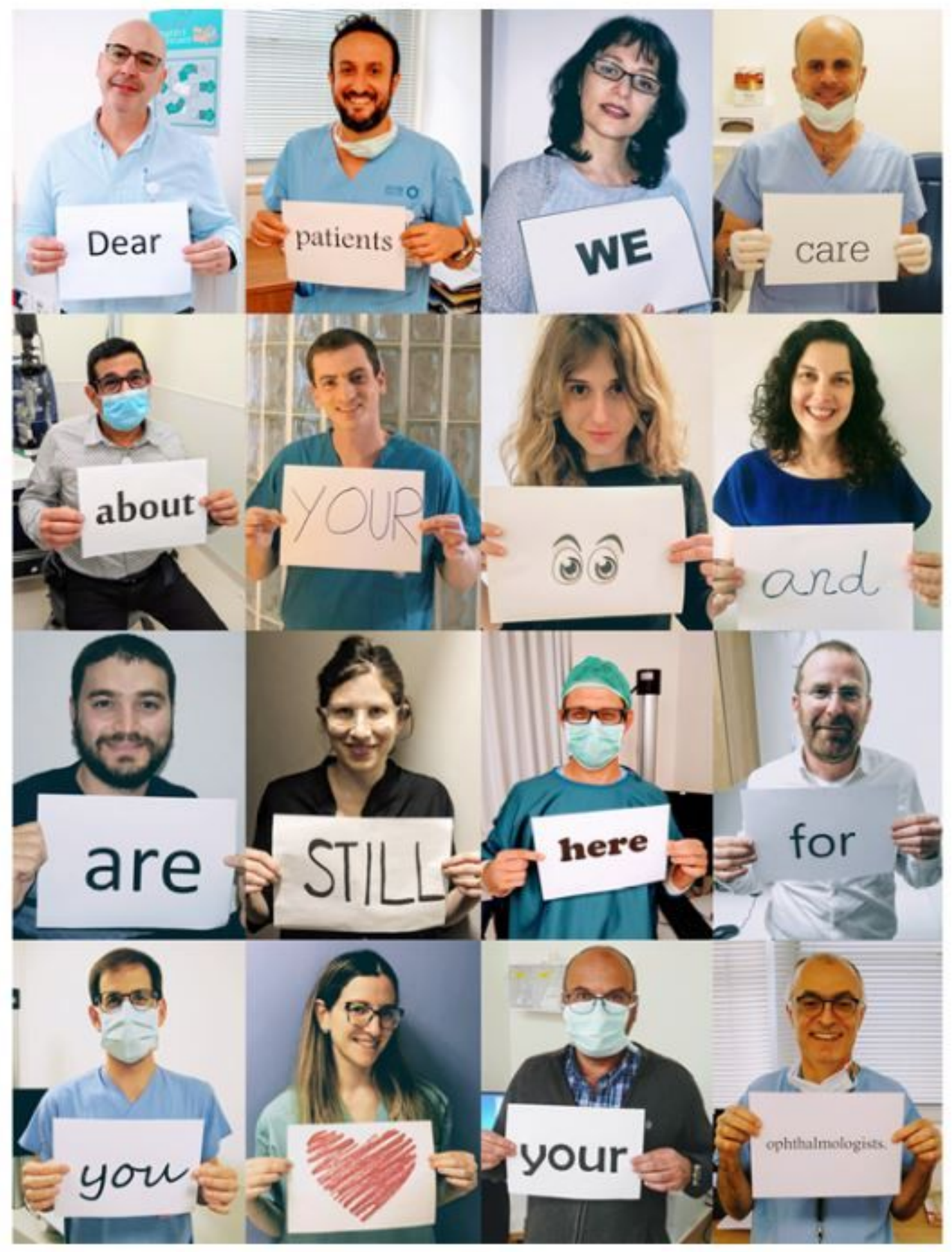

Figure 2

This image was posted on the social media page of Shaare Zedek Medical Center (Facebook and Instagram). It was inspired and adapted from then \#DearPatients postings on social me-dia. https://www.instagram.com/p/B-zmj9lhdgY/. 